\title{
Análise da correlação dos atributos físicos do solo com os componentes de rendimento de grãos de milho em diferentes sistemas de cultivo
}

Analysis of the correlation of soil physical attributes with maize grain yield components in different cultivation systems

Análisis de la correlación de los atributos físicos del suelo con los componentes del rendimiento de grano de maíz en diferentes sistemas de cultivo

\author{
Alexandre da Silva Adão \\ ORCID: https://orcid.org/0000-0003-3534-8990 \\ Instituto Federal do Sudeste de Minas Gerais, Brasil \\ E-mail: alexandre.adao@ifsudestemg.edu.br \\ Haroldo Carlos Fernandes \\ ORCID: https://orcid.org/0000-0001-5276-5441 \\ Universidade Federal de Viçosa, Brasil \\ E-mail: haroldoufv@gmail.com \\ Nerilson Terra Santos \\ ORCID: https://orcid.org/0000-0003-0334-6640 \\ Universidade Federal de Viçosa, Brasil \\ E-mail: nsantos@ufv.br \\ Frederico Cássio Moreira Martins \\ ORCID: https://orcid.org/0000-0002-4400-3903 \\ Instituto Federal do Sudeste de Minas Gerais, Brasil \\ E-mail: frederico.martins@ifsudestemg.edu.br \\ Priscila Souza Pereira \\ ORCID: https://orcid.org/0000-0001-5215-4851 \\ Instituto Federal do Sudeste de Minas Gerais, Brasil \\ E-mail: priscila.pereira@ifsudestemg.edu.br \\ Lucas Moraes Rufini de Souza \\ ORCID: https://orcid.org/0000-0003-4915-9795 \\ Instituto Federal do Sudeste de Minas Gerais, Brasil \\ E-mail: rufinilucas@gmail.com \\ Zenil Ricardo Cunha Rodrigues de Oliveira \\ ORCID: https://orcid.org/0000-0003-0304-6699 \\ Universidade Federal de Viçosa, Brasil \\ E-mail: zenilricardo@gmail.com
}

\begin{abstract}
Resumo
O objetivo do presente trabalho foi analisar a correlação dos atributos físicos do solo com os componentes de rendimento de grãos de milho nos sistemas de cultivo mínimo, preparo convencional e plantio direto. Foi utilizada uma área experimental de aproximadamente 2,13 ha, subdividida em três partes, cada uma delas, recebendo um sistema de manejo de solo. Foram georreferenciados no mínimo 150 pontos em cada uma das três subáreas, utilizando-se de uma malha irregular, e coletadas amostras simples e deformadas de solo nos referidos pontos. Nos pontos definidos, foram avaliados os atributos: umidade gravimétrica, densidade do solo, densidade da partícula, porosidade total e textura. Para avaliação dos componentes de rendimento do milho, foram mensurados: número de fileiras por espiga, número de grãos por fileira, número de grãos por espiga, peso de grãos por espiga e peso de mil grãos da amostra. Realizou-se análise de correlação de Person e análise geoestatística. Os semivariograma cruzados reproduziram satisfatoriamente o comportamento dos atributos que apresentaram dependência espacial no mesmo padrão dos semivariograma simples, possibilitando seu uso para estimar o peso de grãos por espiga.
\end{abstract}

Palavras-chave: Zea mays L.; Geoestatística; Cultivo mínimo; Preparo convencional; Plantio direto.

\begin{abstract}
The aim of this work was to analyze the correlation soil physical attributes of the soil with the components of maize grain yield in minimum tillage, conventional tillage and no-tillage systems. An experimental area of approximately 2.13 ha was used, subdivided into three parts, each one receiving a soil management system. At least 150 points were georeferenced in each of the three sub-areas, using an irregular grid, and simple and deformed soil samples were collected at these points. At the defined points, the following attributes were evaluated: gravity moisture, soil density,
\end{abstract}


particle density, total porosity and texture. To evaluate the components of maize yield, the following were measured: number of rows per cob, number of grains per row, number of grains per cob, weight of grains per cob and weight of thousand grains in the sample. Person correlation analysis and geostatistical analysis were performed. The crossed semivariograms satisfactorily reproduced the behavior of the attributes that presented spatial dependence in the same pattern as the simple semivariograms, allowing its use to estimate the weight of grains per maize.

Keywords: Zea mays L.; Geostatistics; Minimum tillage; Conventional tillage; No-tillage.

\section{Resumen}

El objetivo de este trabajo fue analizar la correlación de los atributos físicos del suelo con los componentes del rendimiento de grano de maíz en sistemas de labranza mínima, labranza convencional y labranza cero. Se utilizó un área experimental de aproximadamente 2,13 ha, subdividida en tres partes, cada una de las cuales recibió un sistema de manejo del suelo. Se georreferenciaron al menos 150 puntos en cada una de las tres subáreas, utilizando una cuadrícula irregular, y en estos puntos se recolectaron muestras de suelo simples y deformadas. En los puntos definidos se evaluaron los siguientes atributos: humedad por gravedad, densidad del suelo, densidad de partículas, porosidad total y textura. Para evaluar los componentes del rendimiento del maíz se midieron: número de hileras por mazorca, número de granos por hilera, número de granos por mazorca, peso de granos por mazorca y peso de mil granos en la muestra. Se realizaron análisis de correlación de personas y análisis geoestadístico. Los semivariogramas cruzados reprodujeron satisfactoriamente el comportamiento de los atributos que presentaron dependencia espacial en el mismo patrón que los semivariogramas simples, permitiendo su uso para estimar el peso de granos por maíz.

Palabras clave: Zea mays L.; Geoestadística; Labranza mínima; Labranza convencional; Labranza cero.

\section{Introdução}

A agricultura de precisão compreende o desenvolvimento e a adoção de técnicas que visam a melhoria do gerenciamento de sistemas de manejos agrícolas, com a finalidade de otimizar aplicações de fertilizantes, pesticidas e sementes, sempre com o objetivo de maximizar a produção agrícola (Bramley et al., 2008). A partir desta ideia, é possível tomar decisões e definir estratégias para cada parte da lavoura, considerando suas particularidades, de modo a contribuir para o aumento da produtividade. As áreas de produção podem ser georreferenciadas e tratadas de maneira diferenciada uma vez que a cultura é perene e vem sendo cultivada em talhões com áreas relativamente pequenas (Queiroz et al., 2004).

De acordo com Antolini e Scare (2015), o estudo da adoção de inovações na agricultura iniciou-se na década de 1950 a 1960. A partir de 1980, a descoberta de novas tecnologias, como o computador, softwares de sistemas de informações geográficas, sensores e técnicas de produção tornaram viável a utilização das técnicas de agricultura de precisão. Colvin et al., (1997) relataram que algumas dessas tecnologias começaram a aparecer no ano de 1989, quando o Sistema de Posicionamento Global, o GPS, passou a ser liberado para uso civil de forma ilimitada, o que possibilitou o crescimento das coletas de informações espacializadas.

A melhor informação do resultado de uma lavoura é a colheita. Na agricultura tradicional a informação sobre a produtividade restringe-se a um valor da média de determinado talhão da propriedade agrícola. Na agricultura de precisão essa informação é o mapa de produtividade de cada porção da lavoura. É uma imagem que representa a variabilidade espacial da produção (Molin \& Castro, 2008).

Segundo Bramley et al. (2008), a agricultura de precisão pressupõe a elaboração e a utilização de mapas que descrevem as características e as propriedades de certa área. Tais mapas representam espacialmente a variabilidade de propriedades do solo, produtividade e características observadas em campo.

Com base nas informações contidas nos mapas, são tomadas as decisões que envolvem o manejo localizado dessas áreas. Nesse sentido, é possível estabelecer uma complementaridade dessas informações para identificar áreas homogêneas (King et al., 2005). Desta forma, os mapas de produtividade se tornaram uma alternativa moderna para gerenciar a variabilidade espacial e temporal de lavouras comerciais, orientando práticas de manejo (Milani et al., 2006).

Segundo Molin e Castro (2008), após apontar as causas e efeitos que determinam a variabilidade na produtividade das culturas, é necessário intervir de maneira localizada, a fim de eliminar ou amenizar tais limitantes. Assim, os mapas de 
produtividade definem a variabilidade espacial da produção de uma cultura no campo, mas não explicam a variabilidade observada (Coelho, 2005), ou seja, indicam as regiões de baixa e alta produtividade, porém não explica as causas de tal variação. Para tanto é necessário o estudo dos fatores que afetam a variação da produtividade. Dentre estes fatores estão os atributos do solo, que por sua vez, não possui tal facilidade para obtenção de dados, sendo um processo muito mais oneroso.

Neste contexto, o objetivo do presente estudo foi analisar a correlação dos atributos físicos do solo com os componentes de rendimento de grãos de milho nos sistemas de cultivo mínimo, preparo convencional e plantio direto.

\section{Material e Métodos}

\section{Características gerais das áreas experimentais}

$\mathrm{O}$ experimento foi conduzido em uma área localizada no município de Barbacena, MG, na mesorregião Campo das Vertentes, situada na longitude $43^{\circ} 45^{\prime} 47^{\prime}$ 'W e latitude $21^{\circ} 14^{\prime} 27^{\prime}$ 'S. O solo da região é classificado como Cambissolo Háplico, segundo a classificação realizada por Dos Santos et al. (2018).

Foi utilizada uma área experimental de aproximadamente 2,13 ha, com o relevo predominantemente montanhoso, e altitude média de $1.200 \mathrm{~m}$. O clima é denominado Cwb temperado e chuvoso (mesotérmico), também chamado subtropical de altitude, classificado de acordo com Köppen (1948). As temperaturas máxima e mínima são $24,4{ }^{\circ} \mathrm{C}$ e $13,8{ }^{\circ} \mathrm{C}$, respectivamente.

A área experimental foi subdividida em três partes e utilizada para o plantio de milho. E cada uma das partes recebeu um sistema de manejo de solo.

A primeira área de tamanho aproximado de 0,87 ha denominada "área 1", recebeu o sistema cultivo mínimo. Em 17/12/2019 houve a aplicação de $1 \mathrm{~L} \mathrm{ha}^{-1}$ de glifosato e, em 23/12/2019, foi realizada dessecação da cobertura vegetal, a adubação de $400 \mathrm{~kg} \mathrm{ha}^{-1}$ com 08-28-16 de NPK e o plantio. Posteriormente, em 21/01/2020, houve aplicação de uma adubação de cobertura de $410 \mathrm{~kg} \mathrm{ha}^{-1}$ de 30-00-20 de NPK.

A segunda área de tamanho aproximado de 0,51 ha, denominada "área 2", recebeu o sistema de preparo convencional. Em 04/12/2019 foi realizada uma aração e, em 17/12/2019, duas gradagens. O plantio foi realizado em 23/12/2019, e adubação de 400 kg ha-1 com 08-28-16 de NPK. Em 17/01/2020 foi aplicado 0,5 L ha-1 de glifosato e, em 21/01/2020, a aplicação de uma adubação de cobertura de $410 \mathrm{~kg} \mathrm{ha}^{-1}$ de 30-00-20 de NPK.

A terceira área do experimento de tamanho aproximado de 0,74 ha, denominada "área 3", recebeu o sistema de plantio direto. Em 17/12/2020, houve aplicação de $1 \mathrm{~L} \mathrm{ha}^{-1}$ de glifosato e, em 23/12/2020, a roçada da área juntamente com o plantio e adubação de $400 \mathrm{~kg} \mathrm{ha}^{-1}$ com 08-28-16 de NPK. Posteriormente, em 21/01/2020, houve aplicação de cobertura de $410 \mathrm{~kg} \mathrm{ha}^{-1}$ de 30-00-20 de NPK.

\section{A Cultura do Milho}

A cultura avaliada neste trabalho foi o Milho (Zea mays L.). Foi utilizado um cultivar híbrido BM855 PRO2 da Biomatrix, de tecnologia VT PRO2. Suas principais características são: ciclo precoce, variando de 120 a 130 dias; estabilidade produtiva; ampla adaptação geográfica, podendo ser plantado tanto no verão como na safrinha; grãos graúdos semidentados de fácil debulha, utilizado para grãos e/ou silagem de grãos úmidos. O estande após o estabelecimento foi de 65.000 plantas ha $^{-1}$. Os espaçamentos foram de $0,65 \mathrm{~m}$ entre linhas e 4,2 plantas $\mathrm{m}^{-1}$.

\section{Coleta de Dados}

\section{Atributos Físicos do Solo}

Uma malha amostral regular foi definida de acordo com a dimensão de cada uma das três áreas, visando obter 
aproximadamente 150 pontos, em cada uma delas.

Desta forma, de posse dos polígonos que delimitam cada uma das áreas, e utilizando o software de sistema de informações geográficas ArcGIS versão 10.1, foram definidas as seguintes malhas amostrais com seus respectivos números de pontos: área 1 com malha amostral de 7,8 m x 7,8 m e 145 pontos; área 2 com malha amostral de 6,2 m x 6,2 m e 140 pontos, área 3 com malha amostral de $7 \mathrm{~m} \times 7 \mathrm{~m}$ e 140 pontos.

Em cada um dos pontos definidos, das três áreas do experimento, foi aberto um perfil no solo com ajuda de um enxadão e de uma pá reta, e coletadas amostras indeformadas de solo nas camadas $0-0,15 \mathrm{~m}$ e $0,15-0,30 \mathrm{~m}$. Tais profundidades foram definidas de acordo com o sistema radicular do milho pois, de acordo com Borém, Galvão e Pimentel (2017), 75\% das raízes encontram-se na camada superficial do solo (0 - 0,20 m).

A amostragem foi realizada de modo que se evitasse a compactação do solo no interior do cilindro, através de uma leve escavação ao seu redor.

As amostras foram coletadas utilizando-se um trado tipo castelinho e anéis volumétricos de $50 \mathrm{~cm}^{3}$, e acondicionadas em cápsulas de alumínio, devidamente numeradas. Em seguida, foram lacradas com fita adesiva e encaminhadas ao laboratório.

\section{Umidade do Solo}

Para a medição da umidade do solo foi utilizado o método gravimétrico padrão, com base na massa de solo seco em estufa à temperatura a $105^{\circ} \mathrm{C}$ até atingir massa constante, conforme Teixeira, Donagemma, Fontana e Teixeira (2017).

A umidade em base gravimétrica foi determinada através da Equação 1:

$C G A=\left(\frac{a-b}{b}\right)$

Onde:

$C G A$, umidade em base gravimétrica, $\mathrm{kg} \mathrm{kg}^{-1}$;

$a$, massa da amostra úmida, $\mathrm{g}$;

$b$, massa da amostra seca a $105^{\circ} \mathrm{C}$ até atingir peso constante, g.

\section{Densidade do Solo}

Para a determinação da densidade de solo foi utilizado o método do anel volumétrico, descrito por Teixeira et al. (2017), caracterizado pela obtenção da massa por pesagem e do volume pela coleta de amostras de solo com estrutura indeformada por meio de um cilindro de volume interno conhecido.

A massa da amostra foi obtida por meio de sua pesagem após secagem em estufa a $105^{\circ} \mathrm{C}$, e o volume, por meio da medida do volume interno do cilindro metálico utilizado na coleta.

A densidade do solo foi determinada através da Equação 2:

$D_{s}=\frac{m_{a}}{V}$

Onde:

$D_{S}$, densidade do solo, $\mathrm{g} \mathrm{cm}^{-3}$;

$m_{a}$, massa da amostra de solo seco a $105^{\circ} \mathrm{C}$ até peso constante, g; 
$V$, volume do cilindro, $\mathrm{cm}^{3}$.

\section{Densidade da Partícula}

Para a determinação da densidade das partículas foi utilizado o método do balão volumétrico descrito por Teixeira $e t$ al. (2017), caracterizado pela obtenção da massa da amostra por pesagem e a determinação de seu volume.

Após a pesagem das amostras úmidas juntamente com seus respectivos recipientes, da transferência para estufa a 105 ${ }^{\circ} \mathrm{C}$ permanecendo pelo tempo de 48 horas até que atingissem peso constante, e de sua retirada da estufa e encaminhamento para o dessecador, foram pesadas e, em seguida, destorroadas.

$\mathrm{Na}$ sequência, foram pesadas $20 \mathrm{~g}$ da amostra de solo e transferidas, com auxílio de um funil, para um balão volumétrico de $50 \mathrm{ml}$ devidamente aferido com água desaerada. Em seguida, com apoio de uma bureta de $50 \mathrm{ml}$, foram adicionados ao balão volumétrico $20 \mathrm{ml}$ de álcool etílico, o qual foi agitado de modo que se eliminasse as bolhas de ar que por ventura viessem a se formar

Após repouso de meia hora, de forma lenta e com o auxílio da bureta de $50 \mathrm{ml}$, foi-se adicionando álcool etílico ao balão volumétrico até que se completasse seu volume. Este volume de álcool etílico, então gasto para que o balão atingisse seu volume, foi anotado.

A densidade da partícula foi determinada através da Equação 3:

$D_{p}=\frac{m_{a}}{\left(v_{T}-V_{U}\right)}$

Onde:

$D_{p}$, densidade da partícula, $\mathrm{kg} \mathrm{dm}^{-3}$;

$m_{a}$, massa da amostra de solo seco a $105^{\circ} \mathrm{C}$ até peso constante, $\mathrm{g}$;

$V_{T}$, volume total aferido do balão, $\mathrm{ml}$;

$V_{U}$, volume utilizado para completar o balão com a amostra, ml.

\section{Porosidade Total}

A porosidade total foi determinada pelo método indireto, descrito por Teixeira et al. (2017), estimada pela relação entre a densidade do solo e a densidade das partículas determinada através da Equação 4:

$P_{t}=\left[\frac{\left(D_{P}-D_{S}\right)}{D_{P}}\right]$

Onde:

$P_{t}$, porosidade total, $\mathrm{m}^{3} \mathrm{~m}^{-3}$;

$D_{P}$, densidade das partículas sólidas do solo, $\mathrm{kg} \mathrm{dm}^{-3}$;

$D_{S}$, densidade do solo, $\mathrm{kg} \mathrm{dm}^{-3}$.

\section{Textura}

A textura foi determinada através da análise granulométrica. Para sua determinação, foi adotado o método da pipeta, descrito por Teixeira et al. (2017). Inicialmente, foi pesada a quantidade de $10 \mathrm{~g}$ de cada amostra de solo, devidamente 
destorroada e peneirada, e transferida com auxílio de um funil, para uma garrafa. Em seguida, foi adicionado $50 \mathrm{ml}$ de solução de hidróxido de sódio $1 \mathrm{~mol} \mathrm{~L}^{-1}$ às garrafas, que foram devidamente numeradas, tampadas e montadas no agitador tipo Wagner, sendo iniciada a agitação por 16 horas a $50 \mathrm{rpm}$. Decorrido o tempo, as garrafas foram retiradas do agitador e deu-se continuidade às demais etapas da análise.

Iniciando o processo de separação de areia, foi montado um conjunto formado por uma peneira de malha $0,053 \mathrm{~mm}$ fixada sobre um funil apoiado numa proveta de $50 \mathrm{ml}$. Todo o material retido na garrafa, inclusive o material contido em sua tampa, foi transferido para a peneira e, devidamente lavado com água deionizada, de forma que a quantidade de areia fosse separada e ficasse retida na peneira. A areia contida na peneira foi descartada, ficando apenas a mistura de argila com silte, depositadas na proveta.

$\mathrm{Na}$ sequência, com auxílio de um bastão com uma tampa de borracha contendo vários furos, a amostra contida na proveta foi vigorosamente agitada por 1 minuto e, em seguida, inserida uma pipeta a $5 \mathrm{~cm}$ e coletado o líquido contendo e argila e silte, que foi imediatamente transferido para um béquer seco, limpo, previamente tarado e identificado.

Após o tempo de sedimentação da fração de silte, determinado em função da temperatura no momento da etapa anterior, a pipeta foi inserida novamente a $5 \mathrm{~cm}$ de profundidade na proveta, onde foi coletado o líquido contendo a argila, que foi imediatamente transferido para um béquer seco, limpo e, previamente tarado e identificado.

Em seguida, os béqueres foram levados para secagem em estufa a $105{ }^{\circ} \mathrm{C}$ por 24 horas e, posteriormente, com os resíduos dos pipetados já secos, foram transferidos para um dessecador até que esfriassem. Por fim, foram pesados em uma balança de precisão. As partículas foram classificadas de acordo com a Sociedade Brasileira de Ciência do Solo: areia, de 2 a 0,05 mm; silte, de 0,05 a 0,002 mm; e argila, menor do que 0,002 mm (Santos, Lemos, Santos, Ker, \& Anjos, 2005).

\section{Resistência do Solo à Penetração}

A resistência do solo à penetração foi avaliada com o auxílio de um penetrômetro de alta precisão e com medição de profundidade por tecnologia ultrassônica, da marca Falker, modelo PLG1020.

Para a realização das medições a estrutura do medidor foi montada. O segmento de haste montável foi atarraxado na haste presa ao módulo eletrônico e, em seguida, o cone foi atarraxado na ponta da estrutura. Também, a base refletora foi colocada no chão no ponto onde se desejou fazer a medição.

$\mathrm{Na}$ sequência, foi medida a força necessária para que a haste penetrasse o solo nas profundidades 0 - $0,15 \mathrm{~m}$ e 0,15 $0,30 \mathrm{~m}$. A inserção da haste foi realizada com velocidade constante para garantir uma medição precisa. Em cada medição foi armazenado um valor de força medido para cada profundidade.

Os dados foram coletados simultaneamente à amostragem do solo para avaliação dos atributos físicos. Os valores de resistência do solo à penetração foram expressos em MPa.

\section{Componentes de Rendimento dos Grãos de Milho}

O processo de colheita das amostras foi iniciado a partir do momento em que o grão do milho atingiu o estágio de maturação fisiológica, ou seja, no instante em que 50\% das sementes da espiga apresentaram pequena mancha preta no ponto de inserção do sabugo (Borém et al., 2017).

A colheita do milho na primeira área do experimento, que recebeu o sistema de cultivo mínimo, foi realizada em 20/05/2020, ou seja, 149 dias após o plantio; na segunda área, que recebeu o sistema de preparo convencional, a colheita foi realizada em 21/05/2020, 150 dias após o plantio; na terceira área, que recebeu o sistema de plantio direto, a colheita foi realizada em 22/05/2020, 151 dias após o plantio.

A colheita foi realizada manualmente nos arredores de cada um dos pontos, onde foram coletadas as amostras para 
análise de solo, não excedendo o distanciamento de $1 \mathrm{~m}$ de raio. Em cada ponto, foram coletadas 5 espigas de milho, que corresponderam à composição de cada amostra.

Em seguida, as espigas correspondentes a cada uma das amostras coletadas foram acondicionadas em saco plástico devidamente identificado, lacradas e encaminhadas para uma sala onde se deu a continuidade do processo.

Foram determinados os seguintes componentes de rendimento da cultura do milho: número de fileiras por espiga (NFE), número de grãos por fileira (NGF), número de grãos por espiga (NGE), peso de grãos por espiga (PGE) e peso de mil grãos da amostra (Pmil, g).

O número de fileiras por espiga (NFE) e o número de grãos por fileira (NGF) foram determinados através da contagem manual das fileiras presentes nas espigas e dos grãos presentes nas fileiras, respectivamente. Em seguida, foi encontrada a média dos cinco valores correspondentes para a composição do valor representante para cada amostra. O número de grãos por espiga (NGE) foi obtido pelo produto entre o número de fileiras das espigas (NFE) e o número de grãos presentes nas fileiras (NGF).

O peso de grãos por espiga (PGE) foi determinado através da debulha e pesagem dos grãos presentes em cada espiga pertencente à amostra, seguindo para a determinação do seu valor médio para a composição do valor correspondente à amostra. O peso de mil grãos da amostra (Pmil, g) foi obtido de forma proporcional ao peso e ao número total dos grãos de cada amostra.

Para a determinação da umidade dos grãos, foram coletadas três amostras aleatórias dos grãos de cada uma das três áreas experimentais e colocadas em estufa a $105{ }^{\circ} \mathrm{C}$ por 24 horas, seguindo-se a metodologia proposta por Brasil (2009). Os grãos foram pesados antes de serem acondicionados na estufa e depois da sua retirada da estufa para determinação, de acordo com a Equação 5, do teor de água na amostra em base úmida.

\section{$U=\frac{P_{i}-P_{f}}{P_{i}} 100$}

Onde:

$U$, teor de água (\% b.u.);

$P_{i}$, massa inicial da amostra $(\mathrm{g})$;

$P_{f}$, massa final da amostra $(\mathrm{g})$.

A umidade considerada para cada uma das três áreas experimentais, foi a média entre os três valores de umidade encontrados através da análise.

Visando a padronização nos resultados do peso de grãos por espiga (PGE), do peso de mil grãos (Pmil, g), e para que os grãos não fossem influenciados por diferentes teores de água, a umidade foi corrigida para 13\% em base úmida, utilizandose a Equação 6:

$M_{f}=\left[1-\left(\frac{U_{i}-U_{f}}{100-U_{i}}\right)\right] M_{i}$

Onde:

$M_{f}$, massa dos grãos com $13 \%$ b.u. (g);

$U_{i}$, teor de água inicial, b.u. (\%); 
$U_{f}$, teor de água final, b.u. (\%);

$M_{i}$, massa das sementes inicial (g).

\section{Análise de Dados}

\section{Correlação De Pearson}

A análise de correlação de Pearson, com teste de significância para hipótese da nulidade (H0, $\rho=0)$, foi utilizada para entender o grau de associação existente entre todos os atributos de solo avaliados e os coeficientes de rendimento de grãos de milho, nos três sistemas de plantio, utilizando-se o software R (Core Team, 2019).

\section{Análise Geoestatística}

Inicialmente para cada atributo, foi analisada a dependência espacial através da obtenção do semivariograma experimental. Para os ajustes, foi utilizado o método dos mínimos quadrados ponderados (Azevedo, Pordeus, Dantas Neto, Azevedo, \& Lima, 2012). Foram utilizados os modelos com patamar denominados isotrópicos: modelo esférico, exponencial e gaussiano (Isaaks \& Srivastava, 1989). Com objetivo de verificar a presença de anisotropia, os semivariogramas foram executados em todas as direções (Yamamoto \& Landim, 2013).

$\mathrm{O}$ ajuste do modelo foi realizado de forma interativa, fazendo um primeiro ajuste e verificando como o modelo teórico se adequou. Os ajustes dos modelos de semivariograma foram efetuados pela seleção inicial do maior coeficiente de determinação $\left(R^{2}\right)$. Os semivariogramas foram revalidados pelo método da validação cruzada.

O índice de dependência espacial (IDE) foi calculado pela Equação 7, conforme metodologia seguida por Cambardella et al. (1994):

$I D E=\left(\frac{c_{0}}{c_{0}+c_{1}}\right) \times 100$

Onde:

$I D E$, índice de dependência espacial;

$C_{0}$, efeito pepita;

$C_{1}$, contribuição.

Para a interpolação dos atributos que apresentaram dependência espacial foi usada a krigagem ordinária, adotando os modelos teóricos estabelecidos.

As análises geoestatísticas foram realizadas através do software R (Core Team, 2019) com apoio das bibliotecas ggplot2 (Wickham, 2016) e gstat (Gräler, Pebesma, \& Heuvelink, 2016).

\section{Resultados e Discussão}

\section{Análise de correlação}

\section{Aspectos Gerais Observados}

Nos três sistemas de plantio, observa forte correlação negativa entre os pares DS1/PT1 e DS2/PT2, indicando que em ambas camadas, à medida que a densidade do solo aumenta a porosidade total diminui significativamente. Tais correlações eram esperadas, uma vez que a porosidade total foi determinada pelo método indireto, e a compressão do solo reduz o tamanho dos poros e aumenta a densidade do solo. Reichert et al., (2009), justificaram que a densidade e a porosidade são atributos 
associados às alterações no volume de solo, sendo relacionados com a compactação do solo, apresentando relação inversa uma com a outra. Chang et al. (2007) e Cunha et al. (2011) também encontraram correlação negativa da DS com a PT.

Observa-se, também, nos três sistemas de plantio, correlação positiva significativa entre os pares DP1/PT1 e DP2/PT2, indicando que a densidade das partículas aumenta à medida que a porosidade total também aumenta, em ambas camadas. Resultados semelhantes foram obtidos por Cruz et al. (2010), onde os autores salientaram que áreas de maior DP correspondem a áreas de maior PT.

Com relação às correlações negativas encontradas entre a RSP e UG, sugere-se que com o aumento da RSP há diminuição da UG. O mesmo pode ser notado nos pares onde houve correlação negativa entre a DS e a UG, indicando que, com o aumento da DS há diminuição da UG. Tais resultados foram semelhantes aos encontrados por Montanari et al. (2013), indicando que solos compactados tendem a ter menor quantidade de água. O PGE e o Pmil estiveram correlacionados positivamente em todos os sistemas de cultivo.

De uma forma geral, foi observado um número maior de correlações significativas no sistema de plantio direto em relação aos sistemas de preparo convencional e cultivo mínimo.

\section{Sistema Cultivo Mínimo}

De acordo com a Tabela 1, com referência à correlação atributos físicos do solo versus atributos físicos do solo, observa-se correlação com significância positiva entre os pares: UG1 e UG2 $\left(0,48^{* *}\right)$, DP1 e PT1 $\left(0,48^{* *}\right)$, DP2 e PT2 $(0,56 * *)$. Foram observadas correlação com significância negativa entre os pares: RSP1 e UG1(-0,14), RSP1 e UG2 (-0,20*), UG2 e DS2 $\left(-0,45^{* *}\right)$, DS1 e PT1 $\left(-0,79^{* *}\right)$, DS2 e PT2 $\left(-0,87^{* *}\right)$.

Tabela 1: Matriz de correlação entre os atributos físicos do solo e os coeficientes de rendimento de grãos de milho mensurados sob o sistema de cultivo mínimo.

\begin{tabular}{|c|c|c|c|c|c|c|c|c|c|c|c|c|c|c|c|}
\hline & RSP1 & RSP2 & UG1 & UG2 & DS1 & DS2 & DP1 & DP2 & PT1 & PT2 & NFE & NGF & NGE & PGE & Pmil \\
\hline RSP1 & 1 & & & & & & & & & & & & & & \\
\hline RSP2 & $0,20 *$ & 1 & & & & & & & & & & & & & \\
\hline UG1 & $-0,14 *$ & 0,11 & 1 & & & & & & & & & & & & \\
\hline UG2 & $-0,20 *$ & $-0,10$ & $0,48 * *$ & 1 & & & & & & & & & & & \\
\hline DS1 & 0,08 & $-0,14$ & $-0,31$ & $-0,36$ & 1 & & & & & & & & & & \\
\hline DS2 & $-0,02$ & $-0,06$ & $-0,24$ & $-0,45 * *$ & 0,32 & 1 & & & & & & & & & \\
\hline DP1 & $-0,05$ & $-0,13$ & $-0,06$ & 0,02 & 0,09 & 0,03 & 1 & & & & & & & & \\
\hline DP2 & 0,06 & $-0,04$ & 0,09 & $-0,02$ & 0,00 & $-0,15$ & 0,20 & 1 & & & & & & & \\
\hline PT1 & $-0,09$ & 0,05 & 0,26 & 0,35 & $-0,79 * *$ & $-0,25$ & $0,48 * *$ & 0,10 & 1 & & & & & & \\
\hline PT2 & 0,02 & 0,03 & 0,27 & 0,39 & $-0,28$ & $-0,87 * *$ & 0,09 & $0,56 * *$ & 0,27 & 1 & & & & & \\
\hline NFE & 0,11 & 0,03 & 0,09 & $-0,03$ & $-0,03$ & 0,12 & $-0,02$ & $-0,13$ & 0,00 & $-0,16$ & 1 & & & & \\
\hline NGF & $-0,18^{*}$ & $-0,02$ & 0,16 & 0,28 & 0,00 & $-0,12$ & 0,07 & $-0,02$ & 0,05 & 0,11 & $-0,08$ & 1 & & & \\
\hline NGE & $-0,06$ & 0,02 & 0,17 & 0,23 & $-0,03$ & $-0,03$ & 0,07 & $-0,10$ & 0,06 & 0,01 & $0,54 * *$ & $\mathbf{0 , 7 8 * *}$ & 1 & & \\
\hline PGE & $-0,13$ & $-0,02$ & 0,20 & 0,14 & $-0,12$ & $-0,07$ & $-0,11$ & 0,01 & 0,06 & 0,08 & 0,27 & $\mathbf{0 , 5 6 * *}$ & $0,63 * *$ & 1 & \\
\hline Pmil & $-0,05$ & 0,01 & 0,15 & $-0,01$ & $-0,06$ & $-0,06$ & $-0,23$ & 0,01 & $-0,06$ & 0,05 & 0,01 & 0,16 & 0,13 & $0,77 * *$ & 1 \\
\hline
\end{tabular}

Significativo a $5 \%$ - *, significativo a $1 \%$ - **, RSPi = resistência do solo à penetração; UGi = umidade gravimétrica; DSi $=$ densidade do solo; $\mathrm{DPi}=$ densidade de partícula; $\mathrm{PTi}=$ porosidade total, $\mathrm{i}=1=0-0,15 \mathrm{~m}$ de profundidade, $2=0,15-0,30 \mathrm{~m}$ de profundidade; NFE = número de fileiras por espiga; $\mathrm{NGF}$ = número de grãos por fileira; $\mathrm{NGE} \mathrm{=} \mathrm{número} \mathrm{de} \mathrm{grãos} \mathrm{por} \mathrm{espiga;} \mathrm{PGE}=$ peso de grãos por espiga; Pmil = peso de mil grãos. Fonte: Autores (2022).

Já a correlação entre os coeficientes de rendimento de grãos de milho versus os coeficientes de rendimento de grãos 
de milho, apresenta correlação com significância positiva entre os pares: NFE e NGE $(0,54 * *)$, NGF e NGE $\left(0,78^{* *}\right)$, NGF e PGE $\left(0,56^{* *}\right)$, NGE e PGE $\left(0,63^{* *}\right)$ e PGE e Pmil $\left(0,77^{* *}\right)$. Não foram observadas correlações com significância negativa.

Analisando a correlação atributos físicos do solo versus coeficientes de rendimento de grãos de milho, observou-se apenas uma correlação e com significância negativa no par RSP1 e NGF $\left(-0,18^{*}\right)$.

\section{Sistema Preparo Convencional}

Segundo a Tabela 2, com referência à correlação atributos físicos do solo versus atributos físicos do solo, observa-se correlação com significância positiva entre os pares: UG1 e UG2 (0,58**), DP1 e DP2 $\left(0,18^{*}\right)$ e DP1 e PT1 $(0,29 * *)$. Foram observadas correlação com significância negativa entre os pares: RSP1 e UG2 (-0,30**), DS1 e PT1 (-0,92**), DS2 e PT2 $(-0,81 * *)$.

Tabela 2: Matriz de correlação entre os atributos físicos do solo e os coeficientes de rendimento de grãos de milho mensurados sob o sistema preparo convencional.

\begin{tabular}{|c|c|c|c|c|c|c|c|c|c|c|c|c|c|c|c|}
\hline & RSP1 & RSP2 & UG1 & UG2 & DS1 & DS2 & DP1 & DP2 & PT1 & PT2 & NFE & NGF & NGE & PGE & Pmil \\
\hline RSP1 & 1 & & & & & & & & & & & & & & \\
\hline RSP2 & $-0,05$ & 1 & & & & & & & & & & & & & \\
\hline UG1 & $-0,13$ & 0,00 & 1 & & & & & & & & & & & & \\
\hline UG2 & $-\mathbf{0 , 3 0} * *$ & 0,08 & $\mathbf{0 , 5 8 * *}$ & 1 & & & & & & & & & & & \\
\hline DS1 & $-0,07$ & 0,11 & $-0,41$ & $-0,14$ & 1 & & & & & & & & & & \\
\hline DS2 & 0,03 & 0,03 & $-0,10$ & $-0,33$ & 0,06 & 1 & & & & & & & & & \\
\hline DP1 & $-0,07$ & $-0,09$ & $-0,11$ & $-0,12$ & 0,05 & 0,06 & 1 & & & & & & & & \\
\hline DP2 & $-0,08$ & 0,00 & 0,01 & 0,00 & $-0,11$ & $-0,01$ & $0,18 *$ & 1 & & & & & & & \\
\hline PT1 & 0,04 & $-0,10$ & 0,33 & 0,07 & $-0,92 * *$ & $-0,05$ & $0,29 * *$ & 0,20 & 1 & & & & & & \\
\hline PT2 & $-0,02$ & $-0,10$ & 0,10 & 0,23 & $-0,10$ & $-0,81 * *$ & $-0,01$ & $0, \mathbf{4 1} * *$ & 0,14 & 1 & & & & & \\
\hline NFE & $-0,03$ & $-0,09$ & $-0,05$ & $-0,05$ & 0,07 & 0,05 & $-0,06$ & 0,10 & $-0,08$ & 0,04 & 1 & & & & \\
\hline NGF & 0,10 & $-0,04$ & $-0,10$ & $-0,08$ & 0,02 & $-0,18$ & 0,07 & 0,06 & 0,01 & 0,24 & 0,03 & 1 & & & \\
\hline NGE & 0,02 & $-0,06$ & $-0,14$ & $-0,07$ & 0,09 & $-0,11$ & 0,05 & 0,12 & $-0,04$ & 0,22 & $\mathbf{0 , 4 8 * *}$ & $\mathbf{0 , 8 1} 1^{* *}$ & 1 & & \\
\hline PGE & $-0,03$ & 0,07 & $-0,06$ & 0,00 & 0,04 & $-0,09$ & $-0,03$ & 0,17 & $-0,04$ & 0,17 & 0,16 & 0,39 & $0,48 * *$ & 1 & \\
\hline Pmil & $-0,09$ & 0,11 & 0,06 & 0,05 & $-0,06$ & $-0,01$ & $-0,04$ & 0,11 & 0,05 & 0,02 & $-0,15$ & $-0,12$ & $-0,14$ & $\mathbf{0 , 7 3} * *$ & 1 \\
\hline
\end{tabular}

Significativo a $5 \%$ - *, significativo a $1 \%$ - **, RSPi = resistência do solo à penetração; UGi = umidade gravimétrica; DSi $=$ densidade do solo; $\mathrm{DPi}=$ densidade de partícula; $\mathrm{PTi}=$ porosidade total, $\mathrm{i}=1=0-0,15 \mathrm{~m}$ de profundidade, $2=0,15-0,30 \mathrm{~m}$ de profundidade; $\mathrm{NFE}=$ número de fileiras por espiga; NGF = número de grãos por fileira; NGE = número de grãos por espiga; $\mathrm{PGE}$ = peso de grãos por espiga; Pmil = peso de mil grãos. Fonte: Autores (2022).

Já a correlação entre os coeficientes de rendimento de grãos de milho versus os coeficientes de rendimento de grãos de milho, apresenta correlação com significância positiva entre os pares: NFE e NGE $\left(0,48^{* *}\right)$, NGF e NGE $\left(0,81^{* *}\right)$, NGE e PGE $\left(0,48^{* *}\right)$ e PGE e Pmil $\left(0,73^{* *}\right)$. Não foram observadas correlações com significância negativa.

Analisando a correlação atributos físicos do solo versus coeficientes de rendimento de grãos de milho, não se observou correlação com significância.

\section{Sistema Plantio Direto}

De acordo com a Tabela 3, com referência à correlação atributos físicos do solo versus atributos físicos do solo, 
observa-se correlação com significância positiva entre os pares: UG1 e UG2 $\left(0,84^{* *}\right)$, UG1 e PT1 $\left(0,16^{* *}\right)$, DS1 e DS2 $\left(0,37^{* *}\right)$, UG2 e PT2 $\left(0,20^{* *}\right)$, DP1 e DP2 $\left(0,29^{* *}\right)$, DP1 e PT1 $\left(0,23^{* *}\right)$, DP2 e PT2 $\left(0,49^{* *}\right)$ e PT1 e PT2 $\left(0,36^{* *}\right)$. Foram observadas correlação com significância negativa entre os pares: RSP1 e PT1 (-0,19*), RSP1 e PT2 (-0,24**), UG2 e DS2 (0,17*), DS1 e PT1 (-0,82**), DS2 e PT1 (-0,39**), DS2 e PT2 (-0,87**).

Tabela 3: Matriz de correlação entre os atributos físicos do solo e os coeficientes de rendimento de grãos de milho mensurados sob o plantio direto.

\begin{tabular}{|c|c|c|c|c|c|c|c|c|c|c|c|c|c|c|c|}
\hline & RSP1 & RSP2 & UG1 & UG2 & DS1 & DS2 & DP1 & DP2 & PT1 & PT2 & NFE & NGF & NGE & PGE & Pmil \\
\hline RSP1 & 1 & & & & & & & & & & & & & & \\
\hline RSP2 & 0,05 & 1 & & & & & & & & & & & & & \\
\hline UG1 & $-0,12$ & 0,09 & 1 & & & & & & & & & & & & \\
\hline UG2 & $-0,09$ & 0,15 & $\mathbf{0 , 8 4} * *$ & 1 & & & & & & & & & & & \\
\hline DS1 & 0,16 & 0,07 & $-0,14$ & $-0,02$ & 1 & & & & & & & & & & \\
\hline DS2 & 0,22 & $-0,02$ & $-0,09$ & $-0,17 *$ & $0,37 * *$ & 1 & & & & & & & & & \\
\hline DP1 & 0,06 & 0,02 & 0,10 & 0,15 & 0,12 & 0,05 & 1 & & & & & & & & \\
\hline DP2 & $-0,09$ & $-0,01$ & 0,05 & 0,10 & 0,04 & $-0,02$ & $0,29 * *$ & 1 & & & & & & & \\
\hline PT1 & $-0,19 *$ & $-0,05$ & $0,16 * *$ & 0,11 & $-0,82 * *$ & $-0,39 * *$ & $0,23 * *$ & 0,08 & 1 & & & & & & \\
\hline PT2 & $-0,24 * *$ & 0,01 & 0,11 & $0,20 * *$ & $-0,29$ & $-0,87 * *$ & 0,10 & $0,49 * *$ & $\mathbf{0 , 3 6 * *}$ & 1 & & & & & \\
\hline NFE & $-0,10$ & $-0,02$ & $-0,06$ & 0,02 & $-0,07$ & $-0,15$ & $-0,12$ & 0,05 & 0,09 & 0,16 & 1 & & & & \\
\hline NGF & $-0,14$ & $-0,08$ & $0,18 *$ & 0,14 & $-0,09$ & $-0,16$ & $-0,02$ & 0,09 & 0,03 & 0,17 & 0,17 & 1 & & & \\
\hline NGE & $-0,16^{*}$ & $-0,10$ & 0,11 & 0,11 & $-0,11$ & $-0,19$ & $-0,06$ & 0,09 & 0,06 & 0,20 & $0,54 * *$ & $0,91 * *$ & 1 & & \\
\hline PGE & $-0,16$ & $-0,11$ & $0,23 * *$ & $0,19 *$ & $-0,11$ & $-0,27$ & $-0,05$ & 0,06 & 0,05 & 0,25 & 0,29 & $\mathbf{0 , 7 8} * *$ & $\mathbf{0 , 7 9} * *$ & 1 & \\
\hline Pmil & $-0,13$ & $-0,08$ & $0,24 * *$ & $0,19 *$ & $-0,10$ & $-0,25$ & $-0,04$ & 0,01 & 0,03 & 0,22 & 0,04 & $\mathbf{0 , 5 0 * *}$ & $\mathbf{0 , 4 5 *}$ & $0,90 * *$ & 1 \\
\hline
\end{tabular}

Significativo a 5\% - *, significativo a $1 \%-* *$, RSPi $=$ resistência do solo à penetração; UGi $=$ umidade gravimétrica; DSi $=$ densidade do solo; $\mathrm{DPi}=$ densidade de partícula; $\mathrm{PTi}=$ porosidade total, $\mathrm{i}=1=0-0,15 \mathrm{~m}$ de profundidade, $2=0,15-0,30 \mathrm{~m}$ de profundidade; $\mathrm{NFE}=$ número de fileiras por espiga; $\mathrm{NGF}$ = número de grãos por fileira; $\mathrm{NGE}$ = número de grãos por espiga; $\mathrm{PGE}=$ peso de grãos por es piga; Pmil = peso de mil grãos. Fonte: Autores (2022).

Já a correlação entre os coeficientes de rendimento de grãos de milho versus os coeficientes de rendimento de grãos de milho, apresenta correlação com significância positiva entre os pares: NFE e NGE $(0,54 * *)$, NGF e NGE $\left(0,91^{* * *}\right)$, NGF e PGE $\left(0,78^{* *}\right)$, NGF e Pmil $\left(0,50^{* *}\right)$, NGE e PGE $\left(0,79^{*}\right)$, NGE e Pmil $\left(0,45^{*}\right)$ e PGE e Pmil $\left(0,90^{* *}\right)$. Não foram observadas correlações com significância negativa.

Analisando a correlação atributos físicos do solo versus coeficientes de rendimento de grãos de milho, observou-se correlação com significância positiva nos pares: UG1 e NGF ( $\left.0,18^{*}\right)$, UG1 e PGE $\left(0,23^{* *}\right)$, UG1 e Pmil $(0,24 * *)$, UG2 e PGE $(0,19 *)$ e UG2 e Pmil $(0,19 *)$. Não foram observadas correlações com significância negativa.

\section{Análise Geoestatística}

\section{Cultivo Mínimo}

A Tabela 4 a seguir, apresenta o resumo dos resultados do ajuste dos semivariogramas cruzados entre o peso de grãos por espiga e os atributos físicos do solo no sistema de cultivo mínimo. 
Tabela 4: Resumo dos resultados do ajuste dos semivariogramas cruzados entre o peso de grãos por espiga e os atributos físicos do solo no sistema de cultivo mínimo.

\begin{tabular}{|c|c|c|c|c|c|c|c|}
\hline Atributo & Modelo & $\begin{array}{c}\text { Efeito pepita } \\
\left(C_{0}\right)\end{array}$ & $\begin{array}{c}\text { Patamar } \\
\left(C_{0}+C_{1}\right)\end{array}$ & $\begin{array}{c}\text { Alcance } \\
\left(A_{0}\right)\end{array}$ & $R^{2}$ & IDE & $\mathrm{E}$ \\
\hline \multicolumn{8}{|c|}{ Atributos físicos do solo } \\
\hline $\mathrm{PGE}=f(\mathrm{RSP} 1)$ & Exponencial & $-0,129$ & $-1,4504$ & 24,87 & $7,95 \%$ & Forte & Peq. \\
\hline $\mathrm{PGE}=f(\mathrm{RSP} 2)$ & Gaussiano & $-0,371$ & $-0,06820$ & 24,87 & $6,28 \%$ & Fraca & Peq. \\
\hline $\mathrm{PGE}=f(\mathrm{UG} 1)$ & Exponencial & $-0,042$ & 0,071014 & 18,87 & $7,68 \%$ & Forte & Peq. \\
\hline $\mathrm{PGE}=f(\mathrm{UG} 2)$ & Gaussiano & $-0,023$ & 0,04453 & 25,84 & $7,44 \%$ & Forte & Peq. \\
\hline $\mathrm{PGE}=f(\mathrm{DS} 1)$ & Exponencial & 0,0526 & $-0,1128$ & 17,39 & $6,66 \%$ & Forte & Peq. \\
\hline $\mathrm{PGE}=f(\mathrm{DS} 2)$ & Exponencial & 0,2629 & $-0,12949$ & 17,39 & $5,73 \%$ & Forte & Peq. \\
\hline $\mathrm{PGE}=f(\mathrm{DP} 1)$ & Exponencial & 0,128 & $-0,1787$ & 17,39 & $8,00 \%$ & Forte & Peq. \\
\hline $\mathrm{PGE}=f(\mathrm{PT} 1)$ & Exponencial & 0,0003 & 0,014357 & 19,94 & $6,18 \%$ & Forte & Peq. \\
\hline $\mathrm{PGE}=f(\mathrm{PT} 2)$ & Exponencial & 0,0970 & 0,24017 & 17,39 & $7,78 \%$ & Forte & Peq. \\
\hline
\end{tabular}

$\mathrm{RSPi}=$ resistência do solo à penetração; $\mathrm{UGi}=$ umidade gravimétrica; $\mathrm{DSi}=$ densidade do solo; $\mathrm{DPi}=$ densidade de partícula; $\mathrm{PTi}=$ porosidade total, $\mathrm{i}=1=0-0,15 \mathrm{~m}$ de profundidade, $2=0,15-0,30 \mathrm{~m}$ de profundidade; $\mathrm{PGE}=$ peso de grãos por espiga; $\mathrm{R}^{2}=$ coeficiente de determinação do modelo de semivariograma; IDE = índice de dependência espacial; $\mathrm{E}=$ grau de aleatoriedade, M.S. = muito significativa, Peq. = pequena. Fonte: Autores (2022).

Para todos os pares formados nos semivariogramas cruzados foi detectada dependência espacial forte, assim como em trabalho conduzido por Montanari et al. (2013). Houve maior predominância de ajuste pelo modelo exponencial, para os atributos: RSP1, UG1, DS1, DS2, DP1, PT1 e PT2. Apenas os atributos RSP2 e UG2 foram ajustados pelo modelo gaussiano.

O valor do alcance dos semivariogramas cruzados indica até que distância as variáveis estão correlacionadas espacialmente (Vieira, 2000). Dessa forma, foram encontrados valores para o alcance indo de 17,39 m para os atributos DS1, DS1, DP1 e PT2, até 24,87 m para a RSP1 e a RSP2.

A seguir é apresentada a Figura 1 com os semivariogramas cruzados entre o peso de grãos por espiga e os atributos físicos do solo e seus respectivos mapas de cokrigagem no sistema de cultivo mínimo. 
Figura 1: Semivariogramas cruzados entre o peso de grãos por espiga e os atributos físicos do solo com seus respectivos mapas de cokrigagem no sistema de cultivo mínimo.

\section{$\mathrm{WGC}=\mathbf{f}(\mathrm{SPR} 1)$}
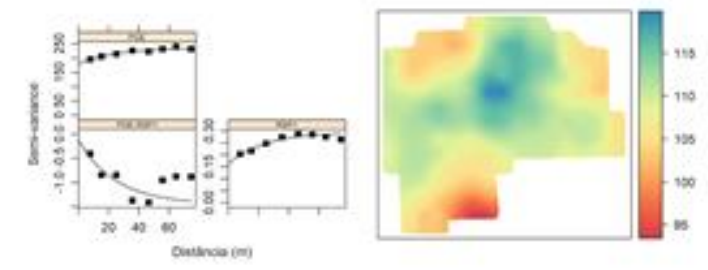

WGC $=\mathbf{f}($ UG1)
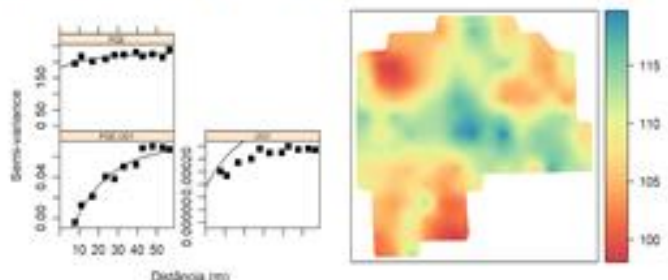

\section{WGC $=\mathbf{f}(\mathrm{DS} 1)$}
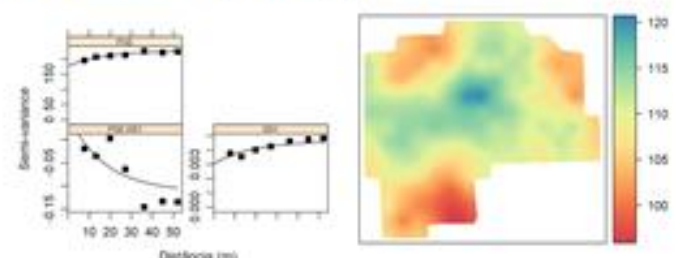

\section{WGC $=\mathbf{f}($ PT1 $)$}
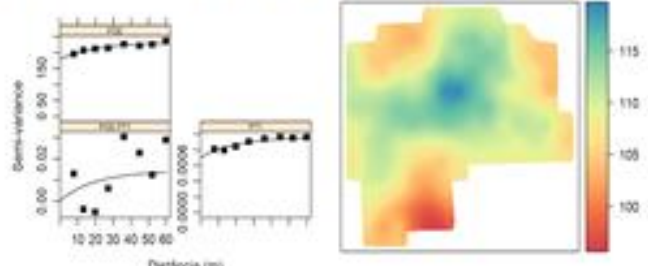

\section{WGC $=\mathbf{f}(\mathrm{DP} 1)$}

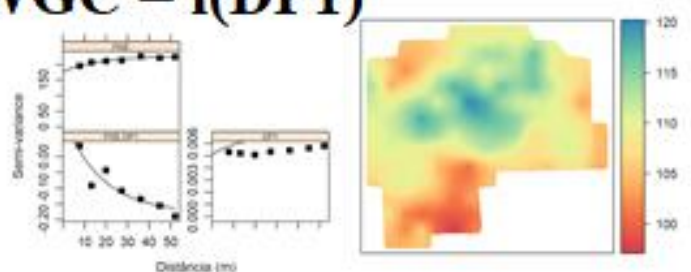

\section{$\mathbf{W G C}=\mathbf{f}($ SPR2 $)$}
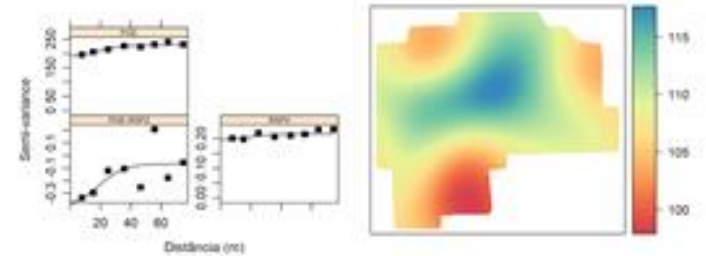

\section{WGC $=\mathbf{f}($ UG2)}
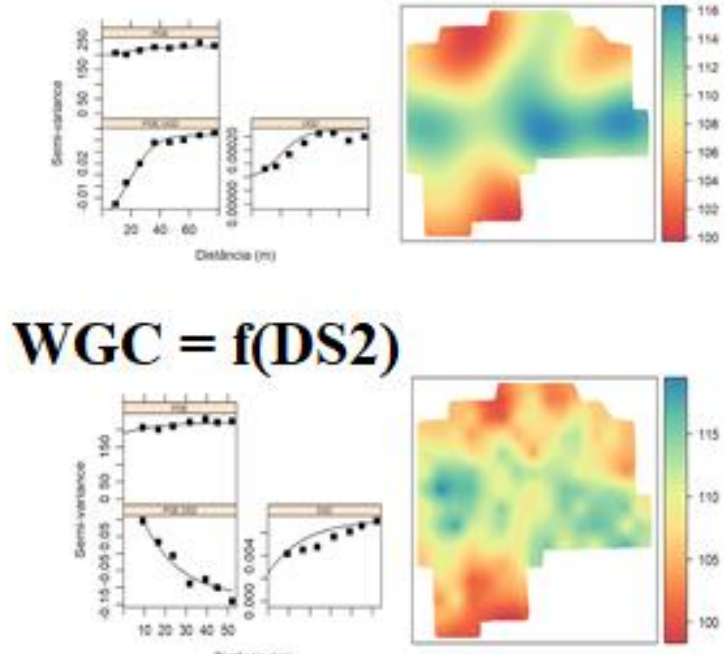

WGC $=\mathbf{f}(\mathbf{P T} 2)$
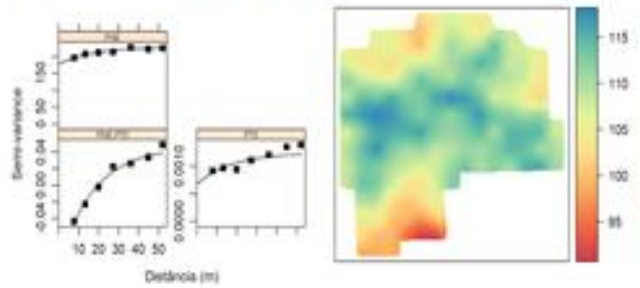

$\mathrm{RSPi}=$ resistência do solo à penetração; UGi = umidade gravimétrica; $\mathrm{DSi}=$ densidade do solo; DPi = densidade de partícula; PTi = porosidade total, $\mathrm{i}=1=0-0,15 \mathrm{~m}$ de profundidade, $2=0,15-0,30 \mathrm{~m}$ de profundidade; PGE $=$ peso de grãos por espiga. Fonte: Autores (2022).

A análise visual dos mapas de isolinhas vai ao encontro dos resultados dos semivariogramas cruzados dos atributos analisados, confirmando a existência de correlação espacial entre o peso de grãos por espiga e os atributos físicos do solo em questão. 
Foram encontradas correlações espaciais positivas entre a PGE e os atributos: UG1, UG2, PT1 e PT2; e negativas entre a PGE e os atributos: RSP1, RSP2, DS1, DS2 e DP1. Tais fatos corroboram com a ideia de que a compactação do solo tem influência negativa na PGE.

\section{Preparo Convencional}

A seguir é apresentada a Tabela 5 com o resumo dos resultados do ajuste dos semivariogramas cruzados entre o peso de grãos por espiga e os atributos físicos do solo no sistema de preparo convencional.

Tabela 5: Resumo dos resultados do ajuste dos semivariogramas cruzados entre o peso de grãos por espiga e os atributos físicos do solo no sistema de preparo convencional.

\begin{tabular}{cccccccc}
\hline Atributo & Modelo & $\begin{array}{c}\text { Efeito pepita } \\
\left(C_{0}\right)\end{array}$ & $\begin{array}{c}\text { Patamar } \\
\left(C_{0}+C_{1}\right)\end{array}$ & $\begin{array}{c}\text { Alcance } \\
\left(A_{0}\right)\end{array}$ & $R^{2}$ & IDE & E \\
\hline PGE $=f($ RSP1 $)$ & Gaussiano & $-0,6134$ & $-0,5836$ & 24,85 & $2,57 \%$ & Fraca & Peq. \\
PGE $=f($ RSP2 $)$ & Exponencial & 0,0678 & 0,80487 & 22,33 & $1,64 \%$ & Forte & Peq. \\
$\mathrm{PGE}=f(\mathrm{UG} 1)$ & Esférico & 0,1691 & $-0,02757$ & 23,39 & $1,33 \%$ & Forte & Peq. \\
$\mathrm{PGE}=f(\mathrm{UG} 2)$ & Exponencial & 0,0032 & 0,00721 & 20,90 & $4,78 \%$ & Moderada & Peq. \\
$\mathrm{PGE}=f(\mathrm{DS} 1)$ & Exponencial & $-0,0056$ & 0,09132 & 21,64 & $3,15 \%$ & Forte & Peq. \\
$\mathrm{PGE}=f(\mathrm{DP} 1)$ & Gaussiano & $-0,0659$ & $-0,030217$ & 23,36 & $2,30 \%$ & Fraca & Peq. \\
$\mathrm{PGE}=f(\mathrm{DP} 2)$ & Exponencial & 0,1113 & 0,1575 & 17,38 & $0,65 \%$ & Forte & Peq. \\
$\mathrm{PGE}=f(\mathrm{PT} 2)$ & Esférico & 0.0748 & 0,0826 & 26,69 & $0,79 \%$ & Fraca & Peq. \\
\hline
\end{tabular}

$\mathrm{RSPi}=$ resistência do solo à penetração; UGi = umidade gravimétrica; $\mathrm{DSi}=$ densidade do solo; $\mathrm{DPi}=$ densidade de partícula; $\mathrm{PTi}=$ porosidade total, $\mathrm{i}=1=0-0,15 \mathrm{~m}$ de profundidade, $2=0,15-0,30 \mathrm{~m}$ de profundidade; $\mathrm{PGE}=$ peso de grãos por espiga; $\mathrm{R}^{2}=$ coeficiente de determinação do modelo de semivariograma; IDE = índice de dependência espacial; $\mathrm{E}=$ grau de aleatoriedade, M.S. = muito significativa, Peq. = pequena. Fonte: Autores (2022).

Com exceção da PGE $=f(U G 2)$ que apresentou dependência espacial moderada, nos demais pares analisados foi detectada a dependência espacial forte. Houve diversificação com relação aos modelos de semivariograma que melhor se ajustaram aos atributos analisados, sendo que a RSP1 e a DP1 foram ajustadas pelo modelo gaussiano, a RSP2, a UG2 e a DS1 pelo modelo exponencial e a UG1 E a PT2 pelo modelo esférico.

Foram encontrados valores para o alcance indo de $17,38 \mathrm{~m}$ para a DP2 até $24,85 \mathrm{~m}$ para a RSP1. Assim, sugere-se que, para trabalhos futuros que utilizem características semelhantes à estas, os valores dos alcances a serem utilizados estejam compreendidos na amplitude descrita, por representarem a distância dentro da qual os valores dos atributos são iguais entre si, como sugerido por Montanari et al. (2013).

A seguir é apresentada a Figura 2 com os semivariogramas cruzados entre o peso de grãos por espiga e os atributos físicos do solo com seus respectivos mapas de cokrigagem no sistema de preparo convencional. 
Figura 2: Semivariogramas cruzados entre o peso de grãos por espiga e os atributos físicos do solo com seus respectivos mapas de cokrigagem no sistema de preparo convencional.

\section{$\mathrm{WGC}=\mathrm{f}(\mathrm{SPR} 1) \quad \mathrm{WGC}=\mathrm{f}(\mathrm{SPR} 2)$}

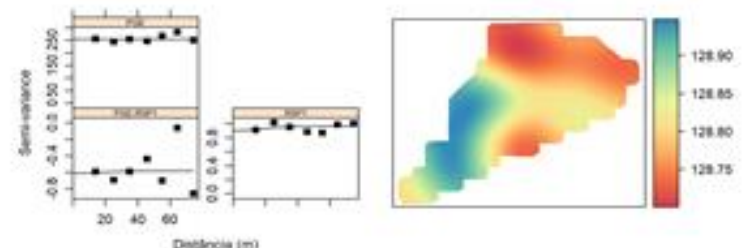

WGC $=\mathbf{f}(\mathbf{U G 1})$

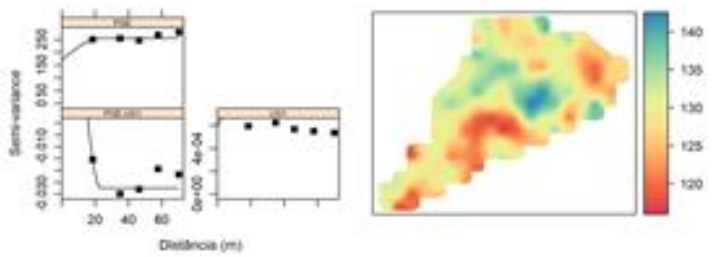

WGC $=\mathbf{f}(\mathrm{DP} 1)$
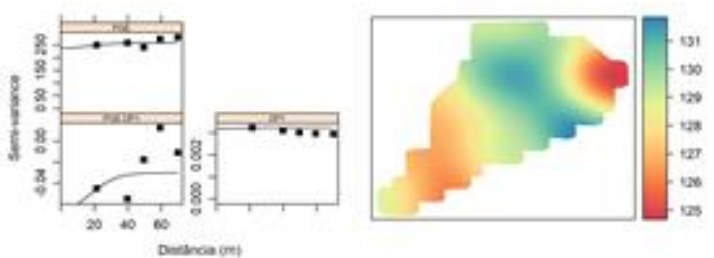

$\mathrm{WGC}=\mathbf{f}(\mathrm{DS} 1)$
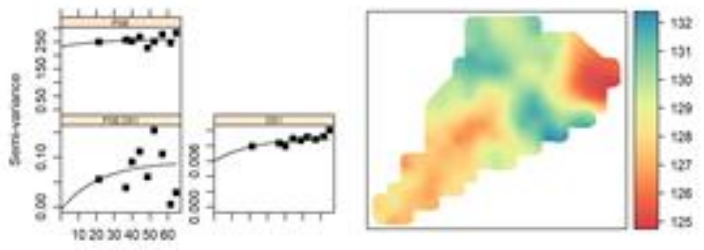

Destreia (m)

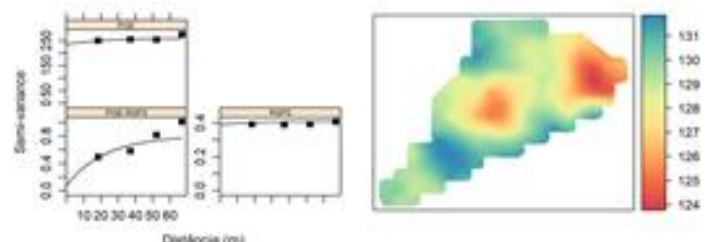

WGC $=\mathbf{f}(\mathbf{U G} 2)$

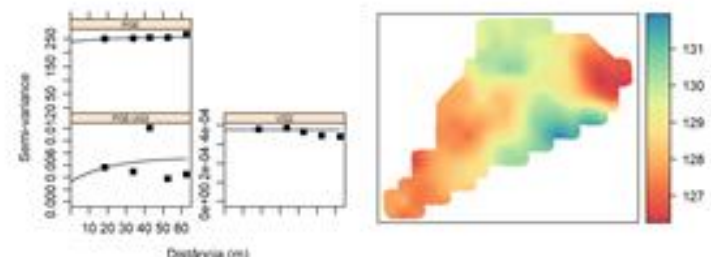

WGC $=\mathbf{f}(\mathbf{D P} 2)$

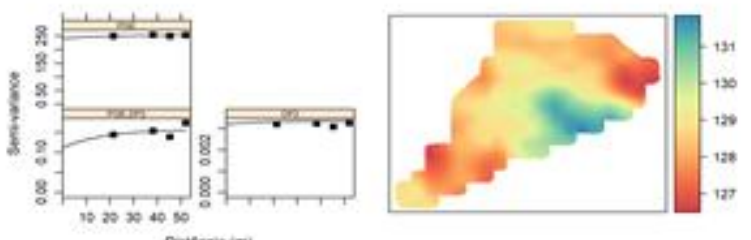

WGC $=\mathbf{f}(\mathbf{P T} 2)$

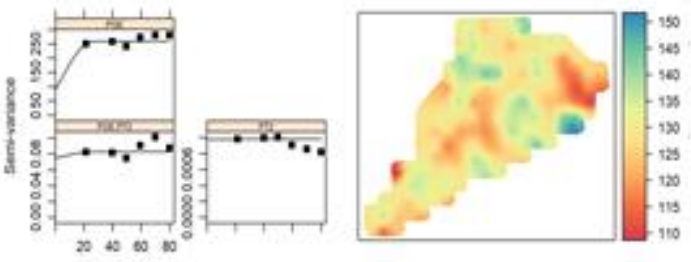

$\mathrm{RSPi}=$ resistência do solo à penetração; UGi = umidade gravimétrica; $\mathrm{DSi}=$ densidade do solo; $\mathrm{DPi}=$ densidade de partícula; $\mathrm{PTi}=$ porosidade total, $\mathrm{i}=1=0-0,15 \mathrm{~m}$ de profundidade, $2=0,15-0,30 \mathrm{~m}$ de profundidade; $\mathrm{PGE}=$ peso de grãos por espiga. Fonte: Autores (2022).

Através da análise visual dos mapas de isolinhas percebe-se a existência de correlação espacial entre o peso de grãos de milho e os atributos físicos do solo. Foram encontradas correlações espaciais positivas entre a PGE e os atributos: RSP2, UG2, DS1, DP2 e PT2; e negativas entre a PGE e os atributos: RSP1, UG1 e DP1. Tais fatos corroboram com o fato da compactação ter influência negativa na PGE. 


\section{Plantio Direto}

A seguir é apresentada a Tabela 6 com o resumo dos resultados do ajuste dos semivariogramas cruzados entre o peso de grãos por espiga e os atributos físicos do solo no sistema de plantio direto.

Tabela 6: Resumo dos resultados do ajuste dos semivariogramas cruzados entre o peso de grãos por espiga e os atributos físicos do solo no sistema de plantio direto.

\begin{tabular}{cccccccc}
\hline Atributo & Modelo & Efeito pepita $\left(C_{0}\right)$ & $\begin{array}{c}\text { Patamar } \\
\left(C_{0}+C_{1}\right)\end{array}$ & $\begin{array}{c}\text { Alcance } \\
\left(A_{0}\right)\end{array}$ & $R^{2}$ & IDE & E \\
\hline PGE $=f(\mathrm{RSP} 1)$ & Exponencial & 2,888 & $-6,2524$ & 34,96 & $36,53 \%$ & Forte & Peq. \\
$\mathrm{PGE}=f(\mathrm{RSP} 2)$ & Gaussiano & $-1,968$ & $-0,7335$ & 34,96 & $34,97 \%$ & Fraca & Peq. \\
$\mathrm{PGE}=f(\mathrm{UG} 1)$ & Gaussiano & $-0,01214$ & 0,10748 & 28,39 & $34,92 \%$ & Forte & Peq. \\
$\mathrm{PGE}=f(\mathrm{UG} 2)$ & Gaussiano & $-0,0371$ & 0,09496 & 28,39 & $35,58 \%$ & Forte & Peq. \\
$\mathrm{PGE}=f(\mathrm{DS} 1)$ & Exponencial & $-0,160$ & 0,0900 & 13,95 & $33,69 \%$ & Forte & Peq. \\
$\mathrm{PGE}=f(\mathrm{DS} 2)$ & Exponencial & 0,0867 & $-0,19705$ & 17,49 & $34,11 \%$ & Forte & Sig. \\
$\mathrm{PGE}=f(\mathrm{PT} 1)$ & Exponencial & 0,00846 & $-0,04027$ & 14,65 & $33,64 \%$ & Forte & Peq. \\
$\mathrm{PGE}=f(\mathrm{PT} 2)$ & Exponencial & $-0,01076$ & 0,070279 & 12,98 & $34,13 \%$ & Forte & Peq. \\
\hline
\end{tabular}

RSPi = resistência do solo à penetração; UGi = umidade gravimétrica; DSi = densidade do solo; DPi = densidade de partícula; PTi = porosidade total, $\mathrm{i}=1=0-0,15 \mathrm{~m}$ de profundidade, $2=0,15-0,30 \mathrm{~m}$ de profundidade; $\mathrm{PGE}=$ peso de grãos por espiga; $\mathrm{R}^{2}=$ coeficiente de determinação; IDE = índice de dependência espacial; $\mathrm{E}=$ grau de aleatoriedade, M.S. = muito significativa, Peq. = pequena. Fonte: Autores (2022).

Assim como em trabalho de Montanari et al. (2013), para todos os pares formados nos semivariogramas cruzados foi detectada dependência espacial forte. Houve predominância de ajuste pelo modelo exponencial para os atributos: RSP1, DS1, DS2, PT1 e PT2; e pelo modelo gaussiano para os atributos: RSP2, UG1 e UG2.

Foram encontrados valores para o alcance indo de 17,49 m para os atributos DS1, DS1, DP1 e PT2, até 34,96 m para a RSP1 e a RSP2.

A seguir é apresentada a Figura 3 com os semivariogramas cruzados entre o peso de grãos por espiga e os atributos físicos do solo com seus respectivos mapas de cokrigagem no sistema de plantio direto. 
Figura 3: Semivariogramas cruzados entre o peso de grãos por espiga e os atributos físicos do solo com seus respectivos mapas de cokrigagem no sistema de plantio direto.

\section{$\mathrm{WGC}=\mathrm{f}(\mathrm{SPR} 1) \quad \mathrm{WGC}=\mathrm{f}(\mathrm{SPR} 2)$}

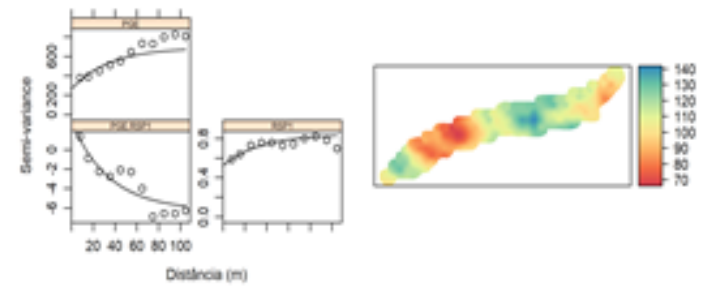

$\mathbf{W G C}=\mathbf{f}(\mathbf{U G 1})$
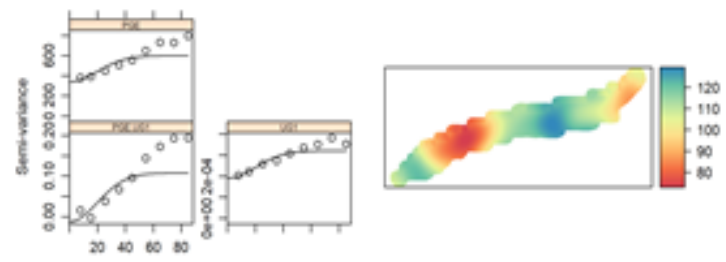

WGC $=\mathbf{f}(\mathrm{DS} 1)$
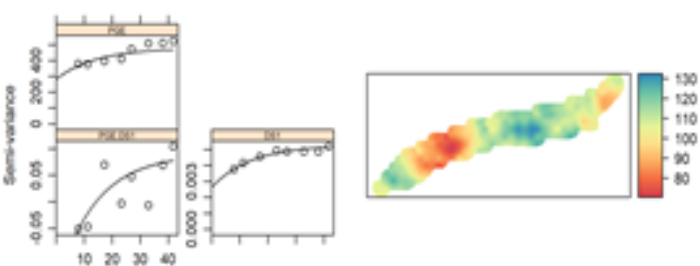

WGC $=\mathbf{f}(\mathbf{P T} 1)$
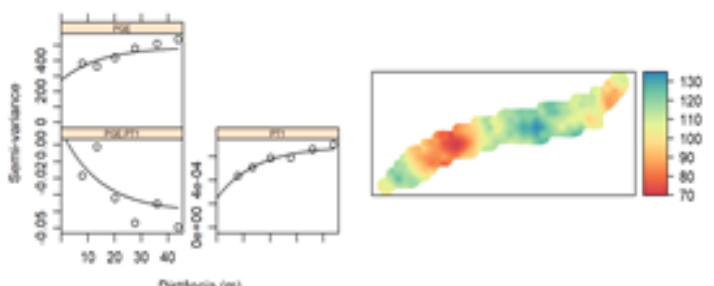

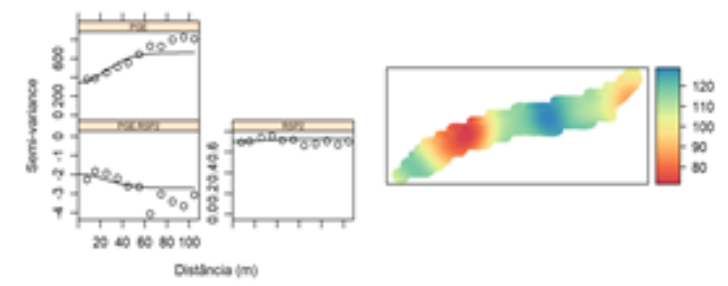

WGC $=\mathbf{f}(\mathbf{U G 2})$
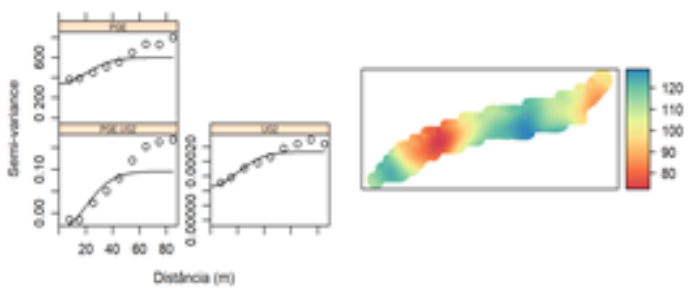

WGC $=\mathbf{f}(\mathrm{DS} 2)$
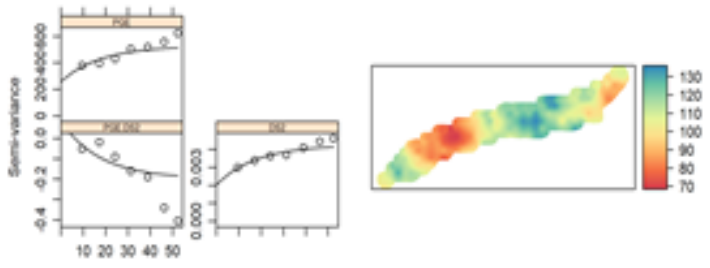

\section{WGC $=\mathbf{f}(\mathbf{P T} 2)$}
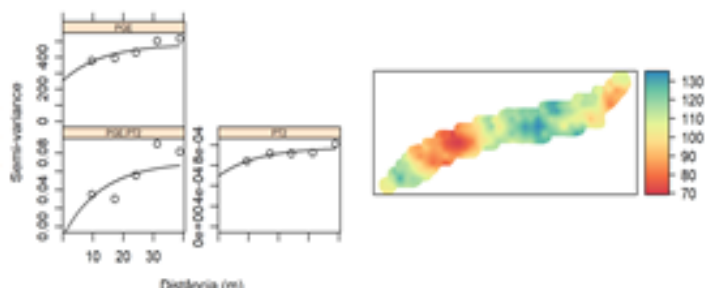

$\mathrm{RSPi}=$ resistência do solo à penetração; $\mathrm{UGi}=$ umidade gravimétrica $; \mathrm{DSi}=$ densidade do solo $;$ DPi $=$ densidade de partícula; $\mathrm{PTi}=$ porosidade total, $\mathrm{i}=1=0-0,15 \mathrm{~m}$ de profundidade, $2=0,15-0,30 \mathrm{~m}$ de profundidade; $\mathrm{PGE}=$ peso de grãos por espiga.

Fonte: Autores (2022).

Foram encontradas correlações espaciais positivas entre a PGE e os atributos: UG1, UG2, DS1 e PT2; e negativas entre a PGE e os atributos: RSP1, RSP2, DS2 e PT1. Tais fatos corroboram com os resultados encontrados na avaliação da correlação linear, onde foram encontradas correlações com significância positiva entre os pares: UG1/PGE e UG2/ PGE. 


\section{Conclusão}

As malhas de amostragem utilizadas foram adequadas pois permitiram representar a dependência espacial dos atributos analisados, possibilitando a criação dos mapas de isolinhas para observação da distribuição espacial dos atributos nas áreas experimentais.

Os semivariograma cruzados reproduziram satisfatoriamente o comportamento dos atributos que apresentaram dependência espacial no mesmo padrão dos semivariograma simples, possibilitando seu uso para estimar o peso de grãos por espiga.

\section{Referências}

Antolini, L. S., \& Scare, R. F. (2015). Adoption of precision agriculture technologies by farmers: A systematic literature review and proposition of an integrated conceptual framework. International food and agribusiness management association. https://www.semanticscholar.org/paper/adoption-of-precisionagriculture-technologies-by-\%3a-antolini-scare/227f4c67ef4e835ddbb0e6a01ba7ae5b91741a44

Argenton, J., Albuquerque, J. A., Bayer, C., \& Wildner, L. P. (2005). Comportamento de atributos relacionados com a forma da estrutura de Latossolo Vermelho sob sistemas de preparo e plantas de cobertura. Revista Brasileira de Ciência do Solo, 29, 425-435. doi.org/10.1590/S0100-06832005000300013

Azevedo, C. A. V., Pordeus, R. V., Dantas Neto, J., Azevedo, M. R. Q. A., \& Lima, V. L. A. (2012). Dependência espacial da qualidade da água subterrânea no perímetro irrigado de São Gonçalo, Paraíba. Revista Verde de Agroecologia e Desenvolvimento Sustentável, 7(2), 129-136. https://dialnet.unirioja.es/servlet/articulo?codigo=7412143

Borém, A., Galvão, J. C. C., \& Pimentel, M. A. (2017). Milho: do plantio à colheita. Editora UFV.

Bramley, R. G. V., Hill, P. A., Thorburn, P. J., Kroon, F. J., \& Panten, K. (2008). Precision agriculture for improved environmental outcomes: Some Australian perspectives. Landbauforschung - vTI Agriculture and Forestry Research, 3(58), 161-178. https://www.researchgate.net/publication/230667539_Precision_Agriculture_for_improved_environmental_outcomes_Some_Australian_perspectives_Landba uforschung-vTi

Brasil. (2009). Regras para análise de sementes. Ministério da Agricultura, Pecuária e Abastecimento.

Cambardella, C. A., Moorman, T. B., Novak, J. M., Parkin, T. B., Karlen, D. L., Turco, R. F., \& Konopka, A. E. (1994). Field-scale variability of soil properties in central Iowa soils. Soil Science Society of America Journal, 58(5), 1501-1511. doi.org/10.2136/sssaj1994.03615995005800050033x

Coelho, A. M. (2005). Agricultura de precisão: manejo da variabilidade espacial e temporal dos solos e das culturas. Sete Lagoas, Embrapa Milho e Sorgo. https://www.infoteca.cnptia.embrapa.br/bitstream/doc/489734/1/Doc46.pdf

Colvin, T. S., Jaynes, D. B., Karlen, D. L., Laird, D. A., \& Ambuel, J. R. (1997). Yield variability within a central Iowa field. International Journal of the American Society of Agricultural and Biological Engineers, 40(4), 883-889. doi.org/10.13031/2013.21336

Core Team, R. C. T. R. (2019). R: A Language and Environment for Statistical Computing. Vienna, R Foundation for Statistical Computing. https://www.Rproject.org/

Cruz, J. S., Assis Júnior, R. N., Matias, S. S. R., Camacho-Tamayo, J. H., \& Tavares, R. C. (2010). Análise espacial de atributos físicos e carbono orgânico em argissolo vermelho-amarelo cultivado com cana-de-açúcar. Ciência e Agrotecnologia, 34(2), 271-278. doi.org/10.1590/S1413-70542010000200001

Cunha, E. Q., Stone, L. F., Moreira, J. A. A., Ferreira, E. P. B., Didonet, A. D., \& Leandro, W. M. (2011). Sistemas de preparo do solo e culturas de cobertura na produção orgânica de feijão e milho: I - atributos físicos do solo. Revista Brasileira de Ciência do Solo, 35 (2), 589-602. doi.org/10.1590/S010006832011000200028

Dos Santos, H. G., Jacomine, P. K. T., Anjos, L. H. C., Oliveira, V. A., Lumbreras, J. F., Coelho, M. R., Almeida, J. A., Filho, J. C. A., Oliveira, J. B., \& Cunha, T. $\quad$ J. F. (2018). Sistema Brasileiro de Classificação de Solos. Brasília-DF, Embrapa. https://www.infoteca.cnptia.embrapa.br/infoteca/handle/doc/1094http://www.infoteca.cnptia.embrapa.br/infoteca/handle/doc/109400303

Gräler, B., Pebesma, E., \& Heuvelink, G. (2016). Spatio-Temporal Interpolation using gstat. The R Journal, 8(1), 204-218. doi.org/10.32614/rj-2016-014

Isaaks, E. H., \& Srivastava, R. M. (1989). An introduction to applied geostatistics. New York, Oxford University Press.

King, J. A., Bradley, R. I., Dampney, P. M. R., Lark, R. M., Mayr, T. R., \& Wheejer, H. C. (2005). Mapping Potential Crop Management Zones within Fields: Use of Yieldmap Series and Patterns of Soil Physical Properties Identified by Electromagnetic Induction Sensing. Precision Agriculture, 6, 167-181. https://doi.org/10.1007/s11119-005-1033-4

Köppen, W. (1948). Climatologia: con un estudio de los climas de la tierra. Buenos Aires, Fondo de Cultura Económica.

Milani, L., Souza, E. G., Uribe-Opazo, M. A., Gabriel Filho, A., Johann, J. A., \& Pereira, J. O. (2006). Unidades de manejo a partir de dados de produtividade. Acta Scientiarum Agronomy, 28(4), 591-598. doi.org/10.4025/actasciagron.v28i4.937

Molin, J. P., \& Castro, C. N. (2008). Estabelecendo zonas de manejo usando condutividade elétrica do solo e outras propriedades do solo pela técnica de agrupamento difuso. Scientia Agricola, 65(6), 567-573. doi.org/10.1590/S0103-90162008000600001 
Research, Society and Development, v. 11, n. 2, e48611226059, 2022

(CC BY 4.0) | ISSN 2525-3409 | DOI: http://dx.doi.org/10.33448/rsd-v11i2.26059

Montanari, R., Nagel, P. L., Luz, A. P., Silva, E. N. S., Rezende, I. S., Silva, L. V., \& Roque, C. G. (2013). Correlação espacial e temporal de atributos físicos do solo com a produtividade do feijão em Chapadão do Sul-MS. Agrarian, 6(21), 289-302. https://ojs.ufgd.edu.br/index.php/agrarian/article/view/2249

Queiroz, D. M., Pinto, F. A. C., Zandonadi, R. S., Emerich, I. N., \& Sena Júnior, D. G. (2004). Uso de técnicas de agricultura de precisão para a cafeicultura de montanha. Zambolim, L. Efeitos da irrigação sobre a qualidade e produtividade do café. Editora UFV, p.77-108.

Reichert, J. M., Kaiser, D. R., Reinert, D. J., \& Riquelme, U. F. B. (2009). Variação temporal de propriedades físicas do solo e crescimento radicular de feijoeiro em quatro sistemas de manejo. Pesquisa Agropecuária Brasileira, 44(3), 310-319. doi.org/10.1590/S0100-204X2009000300013

Santos, R. D., Lemos, R. D., Santos, H. D., Ker, J. C., \& Anjos, L. D., (2005). Manual de descrição e coleta de solo no campo. Sociedade Brasileira de Ciência do Solo.

Teixeira, P. C., Donagemma, G. K., Fontana, A., \& Teixeira, W. G. (2017). Manual de métodos de análise de solo. Brasília-DF, Embrapa. https://www.embrapa.br/busca-de-publicacoes/-/publicacao/1085209/manual-de-metodos-de-analise-de-solo

Vieira, S. R. (2000). Geoestatística em Estudos de Variabilidade Espacial do Solo. Tópicos em Ciências do Solo. Sociedade Brasileira de Ciência do Solo, 1:153. https://www.researchgate.net/publication/313098532_Geoestatistica_em_estudos_de_variabilidade_espacial_do_solo_In_NOVAIS_R_F_et_al_Eds

Wickham, H. (2016). ggplot2: Elegant Graphics for Data Analysis. Springer-Verlag New York. doi.org/10.1007/978-0-387-98141-3

Yamamoto, J. K., \& Landim, P. M. B. (2013). Geoestatística: conceitos e aplicações. Oficina de textos. 